\title{
Clarifying the criteria for reproductive health counselling for adolescent girls by service providers: A qualitative study.
}

\author{
Zahra Mahdikhani ${ }^{1}$, Sonia Oveisi ${ }^{2}$, Forozan Olfati ${ }^{3 *}$ \\ ${ }^{1}$ School of Nursing and Midwifery, Qazvin University of Medical Sciences, Qazvin, Iran \\ ${ }^{2}$ Medical Faculty, Metabolic Diseases Research Center, Qazvin University of Medical Sciences, Qazvin, Iran \\ ${ }^{3}$ School of Nursing and Midwifery, 'Qazvin University of Medical Sciences, Qazvin, Iran
}

\begin{abstract}
Background: Due to the worldwide priority of adolescent reproductive health and the importance of counselling in them, the purpose of this study was to determine counselling criteria regarding the reproductive health of adolescent girls from the point of view of service providers.

Methods: This is a qualitative study using content analysis method, which was conducted in 2017. Sampling method was purposeful. To collect data, 21 semi-structured interviews were conducted with the participation of midwives and family health care professionals working in health centers. Qualitative content analysis was done. First, the primary codes were extracted from typed interviews. Then the codes were given in the form of short and meaningful concepts. The same concepts were merged and given a general title. In this way, the reproductive health counselling criteria for adolescent girls were extracted.

Results: Reproductive health counselling criteria for adolescent girls was classified in five categories: counselling with educational approach, attention to the effect of intrapersonal, interpersonal and social factors on counselling goals, attention to the relationship of counselling components, attention to referral and triage system, preferential service delivery centers for counselling girls.

Conclusion: Health care providers have provided several criteria for counselling services for adolescents, where attention to the coordination among criteria is of paramount importance in planning for counselling. Additional studies are recommended, especially on referral and triage system in adolescent girls' counselling.
\end{abstract}

Keywords: Reproductive health, Adolescent, Counselling, Providers.

Accepted on April 16, 2018

\section{Introduction}

Adolescence is one of the most important periods of life that can be considered as a time of profound and deep changes and a period of physical, social, and cognitive maturity [1]. The World Health Organization defined adolescence as the age of $10-19$ y that includes about $25 \%$ of the population of some countries [2]. According to UNICEF statistics in 2016, a population of over 1.2 billion of the world's population is adolescents (16\% of the world's population), more than half of them live in Asia [3]. Based on the results of the 2011 census in Iran, $16.34 \%$ of the population of Iran is in the age group of 10-19 y, half of whom are girls [4]. Puberty is the time of fertility and, given the characteristics of puberty in girls, the physical and psychological conditions of this period and the role of girls in reproduction are undoubtedly of particular importance in the health of adolescent girls [5]. Today, due to the special importance of adolescence age, one of the priorities of reproductive health in the world is adolescent reproductive health [6]. An important part of the health of individuals depends on the reproductive health, which is described as having complete physical and psychological health and social well-being, and not just the absence of a disease or disability in all affairs related to the reproductive system and its functioning and processes, including sexual matters [7]. In the latest international talks on adolescents, they concluded that reproductive rights, the right in education and counselling for adolescents, access to reproductive health services, and the promotion of reproductive and sexual health should be addressed [8]; although our health system considers adolescents as vulnerable groups [9].

Considering the risks to which adolescents are exposed, we need intervention programs along with appropriate behavioural changes through counselling, including counselling approaches for AIDS risk reduction, addressing the barriers to safe sexual intercourse, and focusing on the planning of healthy sexual behaviour [10]. Adolescent sexual and reproductive health depends on interventions, such as education and counselling in 
the field of preventing pregnancy, increasing sexual knowledge and increasing the use of preventative and pregnancy reduction measures in adolescents. There are limited evidences showing that these interventions are effective in preventing genderbased violence [11]. Adolescent counselling is a sensitive activity and requires practical knowledge and skills for this process, and behavioural counselling interventions can greatly reduce the main causes of death and illness [12,13]. Among providers, efforts have been made to have a specific view of the needs of this group around the world, which increase the tendency to create adolescent-friendly services [14]. Service providers must have specialized skills for Counselling and interpersonal communication skills [15]. The attitudes of providers to reproductive health of young people are important for counselling [16]. There should be evidence-based guidelines for health care providers to correct their attitudes and improve counselling services for young people [17].

Since the researcher's thoughts are reflected in the questionnaire in the usual research projects that are carried out in a quantitative way, the depth of the attitudes and details of the opinions and beliefs of the interviewees cannot be well found. Therefore, considering the importance of reproductive health counselling in adolescent girls and the lack of adequate research on adolescent girls' counselling about reproductive health, the present research aimed to clarify the counselling criteria from the viewpoint of care providers in the form of a qualitative research that provides a basis for further studies in the field of reproductive health counselling for adolescent girls.

\section{Materials and Method}

Since this study sought to explain the meaning and criteria of counselling, a qualitative approach was used with qualitative content analysis method [18], which was conducted in Iran on Qazvin health care providers, in 2017. The participants in this research included 11 midwifery experts and 7 family health experts (Bachelor). A total of 18 people declared their consent to participate in the research, 3 of whom were excluded due to their unwillingness to continue participating in the study. The number of participants became 15. The selection of the participants was based on the purpose of the study and working experience in the field of adolescent reproductive health counselling. The criteria for entering the study were willingness to participate in the study; counselling for adolescent girls, and exclusion criteria was the lack of knowledge about reproductive health concepts in adolescent girls. Before starting the research, the objectives of the study were explained to the care providers, written consent was obtained, and it was ensured that the information would remain confidential to the researcher.

For simultaneous sampling, two purposeful sampling methods; maximum variation method and theoretical sampling method were used. With the maximum variation sampling method, service providers who were familiar with the concept of reproductive health in adolescents were selected. The theoretical sampling method was used to determine the number of participants and sessions. Interview sessions were followed up to reach the necessary richness in the sense of data saturation.

In order to collect information, an individual interview was conducted with health service providers at the workplace. In this way, face-to-face interviews were held in the presence of the researcher for between 30 and $60 \mathrm{~min}$ by the method of interviewing with semi-structured questions. The questions were consistent with the objectives of the plan and were preposed for guidance and control. These questions are as follows:

1. What is your opinion about the reproductive health of adolescent girls?

2. What counselling goals should a counsellor take into account for the reproductive health counselling for adolescents?

3. What group of girls needs more counselling in your opinion?

4. What centers can provide the best counselling services for adolescent girls in your opinion?

5. What girls need emergency counselling in your opinion?

6. What is your opinion about the conditions for an appropriate counselling on reproductive health of adolescents?

Good communication skills were noted during the interview. Interviews were recorded by a sound recorder. In cases where participants did not want to record sound, the method of writing notes was used. Interviews were typed and printed on paper as soon as possible. The data collection was completed with 21 interviews until reaching saturation.

Data were studied using the thematic analysis method. In this way, the researcher categorizes the data by subject and in some cases, depending on the purpose of the research; the results are reported at this stage. Dickelman's 7-step method was used to analyze data: 1) Read all interviews and texts in order to achieve a general understanding; 2) Write a brief explanatory summary for each interview; 3) Analyze tapes loaded; 4) Return to the interview texts; 5) Compare the interview texts to identify, determine and describe the meanings and the common practice; 6) Identify the patterns related to the subjects; 7) Provide the first draft version from the inside to the commentators to extract their suggestions and apply them in the final version [19].

By repeatedly reviewing the data and immersion in information, sentences and concepts were extracted. The key concepts were placed next to each other, and after the comparison with the researcher's experiences, the main axis was determined and formulated in a schematic model. Then the important points and headings of the text were extracted as open code, taking into account the obvious and hidden content of units of meanings as primary codes (main sentences or concepts). Based on the differences and similarities, these codes were categorized under broader titles (reduction of data to describe the phenomenon and achieve further understanding), and the process of abstraction above was continued until extracting the content. Primary codes that are related to each other and can formulate potential themes were 
grouped into one group. Then each of these potential themes was reviewed and adapted to the statements of the participants, and the main themes were determined. The MAXQDA10 software was employed to manage codes. All Ethical issues (such as conflict of interest, misconduct, co-authorship, double submission, etc.) have been considered carefully. Ethical permission (No. IR.QUMS.REC.1396.119) for the study was obtained from Qazvin University of Medical Sciences in 2017.

\section{Results}

The study was conducted on 15 service providers including 11 midwives and 4 family health professionals. The items extracted from interviews and the results are summarized in the Table 1.

Concerning the acquaintance of girls with the concepts of reproductive health, one of the expert midwives said that: "Concerning the anatomy of the reproductive system of women and men, puberty and reproductive health, nutrition during puberty. At this age, they may be at risk because of the unawareness. In this age we should talk about health and pregnancy, because they will get married soon and the best period is the school time to give the information to them. It is the time they should be informed because AIDS and hepatitis are common; at least we have to say that they are transmitted through sexual contact. We recommend not having out-ofcontext relationships, but if they have a relationship they should not be very much harmed and use condom. Many girls do not know the process of getting pregnant and they may get pregnant because of ignorance and be rejected by the family. At least they have to know to this extent that they use the prevention method and not get pregnant.

Concerning the counselling goals, one of the expert midwives said: Our goal from the reproductive health counselling is to raise their awareness and culture. The goal is to prevent unwanted pregnancy and unprotected relationships. Compared to $10 \mathrm{y}$ ago when we were adolescent, the situation is very different now and our thoughts were different, but now even the elementary school students have a lot of information that are useless to them. Satellite and media have effect but not one hundred percent. We say we have to educate them, because if they do not know from us, they will get information from someone who is unaware and they will be at risk.

Concerning the appropriate conditions for counselling, an expert midwife said: "The environment and space of the center are importance. The title of the center should be such that adolescent not become notorious. Personnel should have sufficient knowledge and skills and can win their confidence, observe the principle of secrecy and can really solve the problem. We sometimes have some limitations. The referral system should be strengthened and the places we are referring to should cooperate with us. It is better that the family comes and has individual counselling and has some group counselling, but sexual issues must be said separately".

Concerned the prioritization of counselling services for adolescent girls, a family expert said: "All girls need counselling. We counsel them not to be in high-risk relationships, all young girls are at risk because of secretion of sex hormones. Some have high priority. For example, parents have out-of-context relationships or are addicted. They make high-risk relationships to earn their money. This is of course seen in high and low economy levels."

Concerning counselling service providing centers for adolescent girls, an expert midwife said: "Nowadays, the adolescent does not know where to go if she has a problem. If there are private centers, they will cost too much that she does not refer to them. Counselling should be either in schools or governmental centers should be available and should be advertised through media to be referred to. We think there should be an adolescent-specialized center, and psychologist counsellor, midwife and health care provider can follow-up to some extent.

Table 1. Main themes, subcategories and main codes extracted the research.

\begin{tabular}{|c|c|c|c|}
\hline Question & Theme & Sub-categories & Codes \\
\hline \multirow{10}{*}{$\begin{array}{l}\text { Girl's } \\
\text { acquaintance } \\
\text { with } \\
\text { reproductive } \\
\text { health } \\
\text { concepts }\end{array}$} & \multirow{10}{*}{$\begin{array}{l}\text { Counseling } \\
\text { with } \\
\text { educational } \\
\text { approach }\end{array}$} & \multirow{9}{*}{ Education content } & - Teaching Life skills in premarital classes. \\
\hline & & & - Teaching women and men genital anatomy. \\
\hline & & & $\begin{array}{l}\text { - Teaching information about the health of puberty, psychological health, sexual health, family } \\
\text { planning, and high-risk sexual relationships to girls. }\end{array}$ \\
\hline & & & - Teaching the appropriate sport and nutrition. \\
\hline & & & - Adolescent girl must know the symptoms and control of premenstrual syndrome. \\
\hline & & & - She must know the causes of infection and the causes of infertility and menstrual disorders. \\
\hline & & & - Giving information about drug addiction and high-risk sexual relationships. \\
\hline & & & - Teaching about AIDS and hepatitis. \\
\hline & & & -Teaching the relationship of adolescent with parents. \\
\hline & & Education place & - Establishing specialized educational centers for adolescents. \\
\hline
\end{tabular}




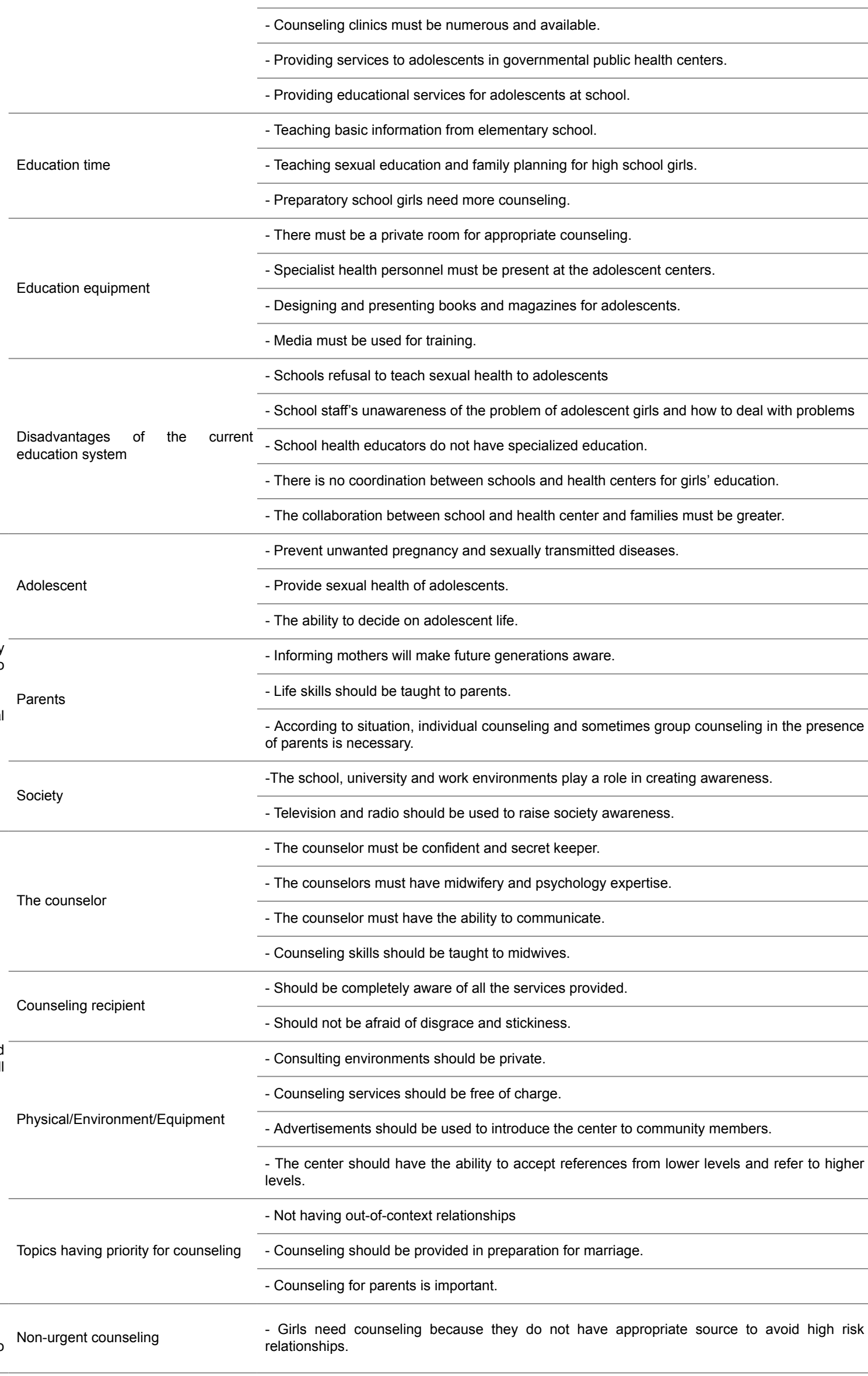




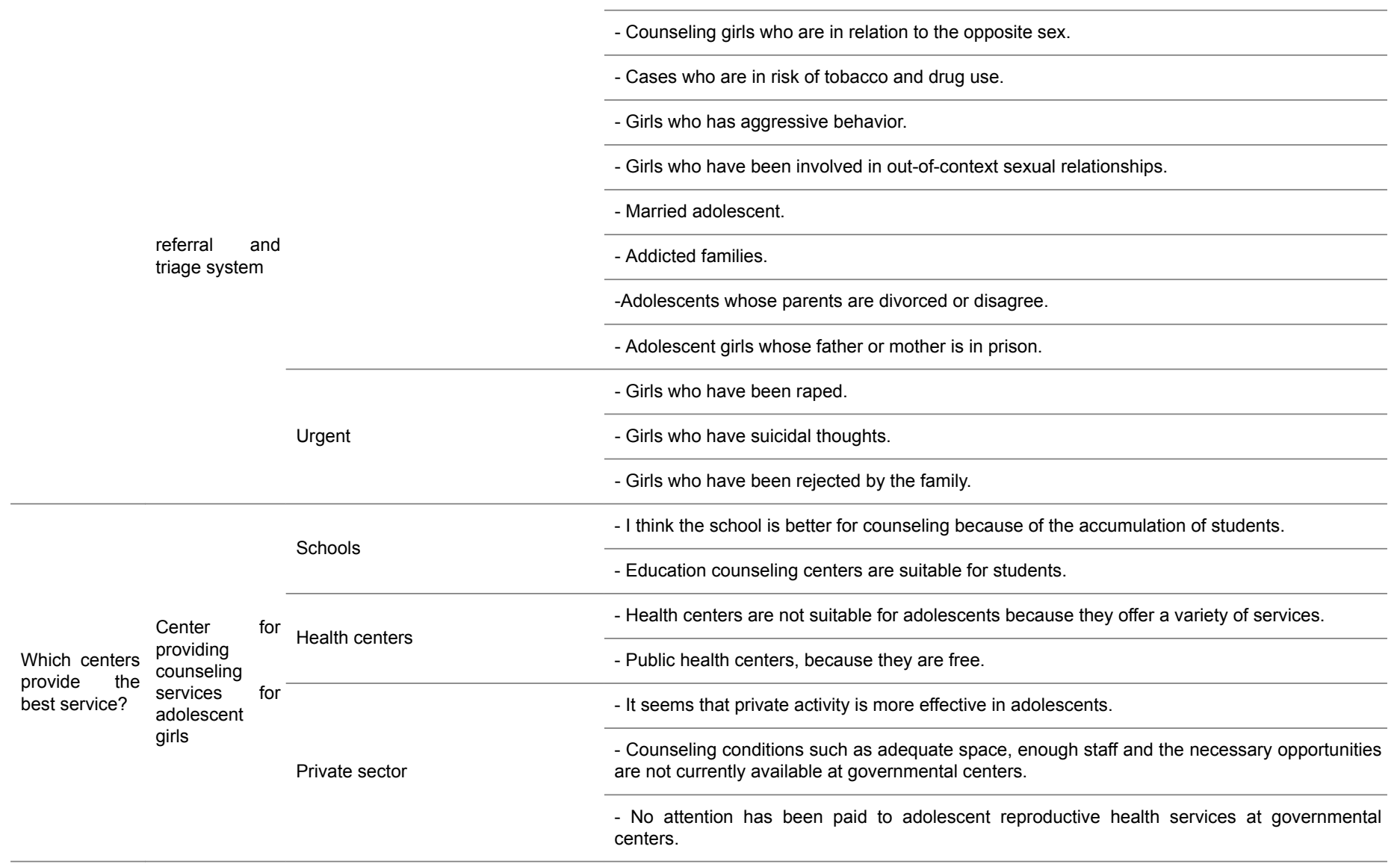

\section{Discussion}

The themes extracted from the research include the following: counselling with educational approach, paying attention to the effect of intrapersonal, interpersonal and social factors on counselling goals, paying attention to the components of counselling, paying attention to referral and triage system in counselling, and centers of providing counselling services for adolescent girls.

Sexual and reproductive health of adolescents depends on interventions, including education and counselling on preventing pregnancy, increasing sexual knowledge and increasing the use of prevention and reduction of adolescent pregnancy [11]. The government, non-governmental organizations, clerics and thinkers, parents, and schools and universities should join the comprehensive education program for educating adolescent girls to create a healthy generation [20]. In a study, the challenges of reproductive health education for adolescent girls were introduced in six axes: lack of adequate awareness and lack of adequate attitude and performance, lack of necessary attention to effective factors on adolescents' awareness and attitudes, and the weakness of information resources for adolescents (mothers, peers, health educators), lack of agreement on the appropriate time to start teaching different dimensions of puberty, lack of adequate educational content for puberty for adolescent girls, and not using appropriate methods for health education for adolescent girls [21].
In this study, most care providers considered sex education essential for adolescent girls and considered the high school age as the best time for this education and the age before entering the university as the best time for family planning education, and few of them preferred that this education be provided upon marriage and in pre-marriage counselling to adolescents and young people, because of the fear of the consequences of this education. All care providers agreed with the education of sexually transmitted diseases and AIDS since early puberty.

The results of a study in 2014 on the appropriate time and methodology of reproductive health education for girls showed that the majority of teachers and parents agreed with sexual education for adolescents, but they preferred that pregnancy and family planning education be provided upon marriage, and AIDS and sexually transmitted diseases education be provided in the high school age. Adolescent girls needed to receive specific skills and awareness in various areas of reproductive health. Given the limitations that schools have in giving girls' sexual awareness, they should consider the transfer of this subjects by teachers in the presence of the parents [22].

In this study, care providers suggested that technology should be used to educate adolescents. In conducted studies, participants also emphasized the use of technology to increase reproductive health services [23], and researches have shown that web-based services have a statistically significant effect on adolescent health behaviours [24]. There are some 
shortcomings in the current educational system such as the lack of awareness of staff of schools about the problems of girls and the lack of communication between schools and health centers and parents. These deficiencies are attributed to parents, health care providers and educators who are not able to provide information to adolescents [25], because they believe that this information encourages sexual activity [26]. The obstacle to providing services to adolescents is the refusal of schools to providing reproductive health services and lack of appropriate resources for adolescents in this field. According to the results of studies conducted in Iran, there is no official reproductive health program in the schools, and this subject is even considered as a taboo [27].

In this study, most service providers also stated that the role of parents is important in providing counselling sessions, and some counselling sessions should be conducted in the presence of parents. After mothers, health educators and peers are the most important sources of information for adolescent girls in this subject [28]. In a study by the Institute of National Health in Italy, parents believed that this education should be provided by doctors [29].

What content is prioritized was controversial from the point of view of the research participants, but the important point was that most of these subjects would be better transferred to the girls in the presence of parents. Many studies have emphasized the importance of the role of mothers [30]. In a study on the content of reproductive health, sexual information is the first priority from the point of view of girls and teachers. As for mothers, the first priority is psychological and social changes in puberty [31]. The first priority for the participants in the present study is physical information, social dimension, communication skills and life skills. The results of the studies show that life skills training can have a positive effect on adolescent girls' psychological health [32].

In our study, providers stated that counsellors should have the ability to communicate with adolescent in order to provide appropriate counselling services, so the counselling skills of midwives should be increased. In the study of Jarosowens too, care providers agreed with the additional training of the staff of health centers and believed that education would improve service providing and communication skills with adolescents [33].

In this study, the necessary condition for counselling from care providers' point of view was to consider all the components of counselling comprehensively. For example, observing confidentiality and the privacy-based counselling were emphasized by care providers. Studies show that individual counselling increases the likelihood of sharing personal problems by the adolescent. However, in cases where the doctor speaks to an adolescent alone, the adolescent does not raise personal issues, particularly sexual ones due to fear of lack of secrecy of the doctor [34]. The Adolescent Medical Society recommends that adolescent health care services and their documents be kept confidential [35].
In our study, the referral system and triage were divided into two categories: urgent and non-urgent but no study was found on the referral system and triage.

Several official organizations have issued evidence-based recommendations to improve the access to reproductive health services for adolescents, which are summarized as ensuring access to services at low cost, providing services for adolescents at the right time and place and guaranteeing adherence to the privacy of the adolescents [36]. They also recommended the availability of appropriate educational resources for adolescence age and the presence of trained staff [37]. The opinions of the participants in our study have also been consistent with these recommendations.

Health care providers proposed several criteria for providing counselling services for adolescents, where attention to the coordination among criteria for planning counselling is of particular importance. Therefore, educational content should be adjusted to the various areas of reproductive health of adolescent girls in accordance with community culture. Attention should be paid to the girls themselves, parents, family, community, school, and the coordination among them. Attention should be paid to the cooperation within the same section and with other sections for finding the best centers for providing counselling services for adolescent girls. Attention should be paid to the secrecy principal and to the privacy of counselled people. The best center is where it can cover all the counselling criteria. Additional studies are recommended, especially on referral and triage system in counselling for adolescent girls.

\section{Financial Disclosure}

The authors have no financial interests related to the material in the manuscript.

\section{Acknowledgement}

This study is the result of a Master's Degree Thesis in Midwifery Consultation approved with ID number IR.QUMS.REC.1396.119. This is to thank the Qazvin University of Medical Sciences for co-operating this project.

\section{References}

1. Blakemore SJ, Burnett S, Dahl RE. The role of puberty in the developing adolescent brain. Human Brain Mapping 2010; 31: 926-933.

2. Brown A, Jejeebhoy SJ, Shah IH, Yount KM, Organization WH. Sexual relations among young people in developing countries: evidence from WHO case studies. WHO 2001.

3. Tegegn A, Yazachew M, Gelaw Y. Reproductive health knowledge and attitude among adolescents: a community based study in Jimma Town, Southwest Ethiopia. Ethiopian J Health Development (EJHD) 2016; 22.

4. Yearbook IS. Statistical center of Iran. Tehran, Iran 2013; 583. 
5. Olfati F, Aligholi S. A study on educational needs of teenage girls regarding the reproductive health and determination of proper strategies in achieving the target goals in Qazvin. J Qazvin Univ Med Sci 2008; 12: 80-82.

6. Hatami H, Razavi S, Eftekhar H, Majlesi F. Comprehensive book of public health. Arjemand Publications, Tehran, Iran 2007; 45-47.

7. Jejeebhoy SJ, Zavier AF, Santhya K. Meeting the commitments of the ICPD programme of action to young people. Reproductive Health Matters 2013; 21: 18-30.

8. Chandra-Mouli V, Svanemyr J, Amin A, Fogstad H, Say L, Girard F. Twenty years after international conference on population and development: where are we with adolescent sexual and reproductive health and rights? J Adolescent Health 2015; 56: S1-S6.

9. Malekafzali H, Simani S, Amirkhani A, Farahtaj F, Hooshmand B, Nadim A. Population control and reproductive health in the Islamic Republic of Iran. Arch Iranian Med 2004; 7: 247-250.

10. Pinto RM. HIV prevention for adolescent groups: A sixstep approach. Social Work with Groups 2001; 23: 81-99.

11. Salam RA, Faqqah A, Sajjad N, Lassi ZS, Das JK, Kaufman M. Improving adolescent sexual and reproductive health: A systematic review of potential interventions. J Adolescent Health 2016; 59: S11-S28.

12. Kanikar A, Bansal C. Adolescent counselling. Indian J Pract Pediatr 2015; 17: 52.

13. McNellis RJ, Ory MG, Lin JS, O’Connor EA. Standards of evidence for behavioral counseling recommendations. Am J Preventive Med 2015; 49: 150-157.

14. Oksenhendler E, Duarte M, Soulier J, Cacoub P, Welker Y, Cadranel J Multicentric Castleman's disease in HIV infection: a clinical and pathological study of 20 patients. AIDS 1996; 10: 61-67.

15. Salam RA, Das JK, Lassi ZS, Bhutta ZA. Adolescent health interventions: Conclusions, evidence gaps, and research priorities. J Adolescent Health 2016; 59: 88-92.

16. Tumlinson K, Pence BW, Curtis SL, Marshall SW, Speizer IS. Quality of care and contraceptive use in urban Kenya. Int Perspectives Sexual Reproductive Health 2015; 41: 69 .

17. Loi UR, Gemzell-Danielsson K, Faxelid E, KlingbergAllvin M. Health care providers' perceptions of and attitudes towards induced abortions in sub-Saharan Africa and Southeast Asia: a systematic literature review of qualitative and quantitative data. BMC Public Health 2015; $15: 139$.

18. Elo $\mathrm{S}, \mathrm{Kyngäs} H$. The qualitative content analysis process. J Adv Nursing 2008; 62: 107-115.

19. Diekelmann N. Narrative pedagogy: Heideggerian hermeneutical analyses of lived experiences of students, teachers, and clinicians. Adv Nursing Sci 2001; 23: 53-71.

20. Wasim T. Adolescent reproductive health education. Ann King Edward Med Univ 2017; 23.

21. Ali-Moradi Z, Simbar M. Challenges of puberty health education for adolescent girls in Iran: Priority for designing a school-based intervention for girls and mothers. Payesh 2014.

22. Mirzaei K, Olfati F. Educational needs of adolescent girls for reproductive health in teachers' views. JQUMS 2014; 18: 67-76.

23. Selkie EM, Benson M, Moreno M. Adolescents' views regarding uses of social networking websites and text messaging for adolescent sexual health education. Am J Health Edu 2011; 42: 205-212.

24. Webb TL, Joseph J, Yardley L, Michie S. Using the internet to promote health behavior change: a systematic review and meta-analysis of the impact of theoretical basis, use of behavior change techniques, and mode of delivery on efficacy. J Med Internet Res 2010; 12.

25. McCauley AP, Salter C, Kiragu K, Senderowitz J. Meeting the needs of young adults. Population Rep Series J 1995; 1-43.

26. Sibanda A, Woubalem Z, Hogan DP, Lindstrom DP. The proximate determinants of the decline to belowreplacement fertility in Addis Ababa, Ethiopia. Studies in Family Planning 2003; 34: 1-7.

27. Vakilian K, Khadijeh Mirzaii N. Reproductive health in Iran: international conference on population and development goals. Oman Med J 2011; 26: 143.

28. Baiali Meibodi F, Mahmodi M, Hasani M. Knowledge and practice of Kerman primary secondary school girls on menstrual health in the academic. J Yasuj Fac Nurs Midwifery 2009; 4: 54-62.

29. Control CFD. Attitudes of parents of high school students about AIDS, drug, and sex education in schools-Rome, Italy, 1991. Morbidity Mortality Weekly Rep 1992; 41: 201.

30. Ali-Moradi Z, Simbar M. Challenges of puberty health education for adolescent girls in Iran: Priority for designing a school-based intervention for girls and mothers. Payesh 2014.

31. Sistani NM, Merghati Khoi E, Taghdisi M. Comparison among viewpoints of mothers, girls and teachers on pubertal health priorities in guidance schools in District 6, Tehran. J School Public Health Institute Public Health Res $2008 ; 6$.

32. Haghighi J, Mosavi M. Effect of life skill training on mental health and self-steem's in first-year students in secondary school an alarm. J Psychol Nurture Cameroon Univ 2006; 1: 61-78.

33. Jaruseviciene L, Orozco M, Ibarra M, Cordova Ossio F, Vega B, Auquilla N. Primary healthcare providers' views on improving sexual and reproductive healthcare for adolescents in Bolivia, Ecuador, and Nicaragua. Global Health Action 2013; 6: 20444.

34. Rubin SE, McKee MD, Campos G, O'sullivan LF. Delivery of confidential care to adolescent males. J Am Board Family Med 2010; 23: 728-735.

35. English A, Park MJ, Shafer M-A, Kreipe RE, D'Angelo LJ. Health care reform and adolescents-an agenda for the 
lifespan: a position paper of the Society for Adolescent Medicine. J Adolescent Health 2009; 45: 310-315.

36. Curtis KM, Tepper NK, Jamieson DJ, Marchbanks PA. Adaptation of the World Health Organization's selected practice recommendations for contraceptive use for the United States. Contraception 2013; 87: 513-516.

37. Kharbanda EO, Levine SB, Burstein GR. Delivering adolescent preventive services in an office setting. Adolescent Med: State of the Art Rev 2011; 22: 482-497.

\section{*Correspondence to}

Forozan Olfati

School of Nursing and Midwifery

Qazvin University of Medical Sciences

Qazvin

Iran 